\title{
A Study on Clinico-Epidemiological Profile of Poisoning in Children in a Rural Tertiary Care Hospital
}

\author{
Sil A', Ghosh TN², Bhattacharya $\mathrm{S}^{3}$, Konar MC ${ }^{4}$, Soren $\mathrm{B}^{5}$, Nayek $\mathrm{K}^{6}$
}

${ }^{1}$ Dr. Archan Sil, MBBS, MD. RMO cum Clinical Tutor, ${ }^{2} \mathrm{Dr}$. Tarak Nath Ghosh, MBBS, MD. Associate Professor, ${ }^{3} \mathrm{Dr}$. Sudipta Bhattacharya, MBBS, MD. Senior Resident, ${ }^{4} \mathrm{Dr}$. Mithun Chandra Konar, MBBS, MD. Assistant Professor, ${ }^{5} \mathrm{Dr}$. Baisakhi Soren, MBBS, MD. Assistant Professor, ${ }^{6}$ Dr. Kaustav Nayek, MBBS, MD. Professor. All from the Department of Paediatric Medicine, Burdwan Medical College, Burdwan, West Bengal, India.

\section{Address for correspondence: \\ Dr. Archan Sil \\ Department of Pediatric Medicine \\ Burdwan Medical College, \\ Aftab Avenue, Burdwan. \\ West Bengal, India. \\ Tel: +919051983804 \\ E-mail: sayarch84@gmail.com}

Acknowledgements: The authors would like to express their gratitude to the residents of department of Paediatrics, Burdwan Medical College for their cooperation.

Funding: Nil

Conflict of Interest: None

Permission from IRB: Yes

Ethical dilemmas faced during study: No

\section{How to cite}

Sil A, Ghosh TN, Bhattacharya S, Konar MC, Soren B, Nayek K. Prevalence of Wasting, A Study on Clinico-Epidemiological Profile of Poisoning in Children in a Rural Tertiary Care Hospital. J Nepal Paediatr Soc 2016;36(2):105109.

doi: http://dx.doi.org/10.3126/jnps.v36i2.15040

This work is licensed under a Creative Commons Attribution 3.0 License.

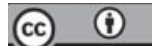

\begin{abstract}
Introduction: Poisoning is an important cause of morbidity and mortality in paediatric age group. Objective of this study was to determine the pattern of poisoning in paediatric age group in respect to epidemiological characteristics, aetiology, clinical features and mortality in a major part of South Bengal. Material and Methods: This was a retrospective, observational study conducted in the paediatric medicine ward and paediatric intensive care unit (PICU) of Burdwan Medical College from January, 2015 to December, 2015.All children in the age group of less than or equal to 12 years who visited the paediatric emergency with history of exposure to toxic substances were included in the study. Poisoning due to insect or animal bite was excluded from the study. Data was obtained from hospital records and the admission register of paediatric emergency, entered in the Microsoft excel sheet and analysed by using statistical software SPSS version 17. Results: During the study period, 393 patients with poisoning were reported, which was $1.9 \%$ of all pediatric admissions. Majority were in the $1-3$ year age group (59.6\%). Volatile hydrocarbons accounted for the highest proportion of poisonings (153 cases, 38.9\%).. GI system involvement $(36.5 \%)$ was most common. The total mortality of poisoning patients was 8 . Conclusion: Number of children, presenting with poisoning was higher in our study in comparison to other studies. Volatile hydrocarbons were common source of poisoning in our study. More epidemiological studies are required to identify socio-demographic risk factors of poisoning.
\end{abstract}

Key words: Poisoning, Children, Hydrocarbon

\section{Introduction}

$\mathrm{P}$ oisoning is exposure of an individual to a substance that can cause damage or injury to the body and endangers one's life due to organ dysfunction ${ }^{1,2}$. Poisoning in paediatric patients is a common cause of morbidity and mortality ${ }^{3,4,5}$. It is usually accidental in this age group. Several epidemiological studies on accidental poisoning in children show consistent age and gender distribution with predominance in male children of less than six years ${ }^{6}$. 
Various agents like household substances, agrochemicals, drugs or environmental agents are implicated as poisoning agents. Lack of maternal knowledge, improper storage of substances and insufficient supervision are the major causes of paediatric poisoning ${ }^{3}$.

In a specific region prevalent social, economic and cultural practices play an important role in influencing profile of poisoned paediatric patients. According to American Poison Control Centre ingestion is the major route of poisoning ${ }^{7}$. Incidence of poisoning in children from 1994 to 2003 was 450 per 100000 population as per data from consumer product safety commission ${ }^{8}$.

Despite latest medical advances and safety campaigns, the incidence of toxin related injuries due to different chemicals and drugs are on the rise. The exact magnitude of this problem is difficult to establish. In this study, conducted in a rural tertiary care hospital of West Bengal, attempts were made to assess epidemiological characteristics, aetiology, clinical presentation and mortality in affected children.

The objectives of this study were to determine demographic characteristics, incidence, aetiology, clinical manifestations of poisoning in paediatric age group in a major part of South Bengal and their immediate outcome.

\section{Material and Methods}

This study was conducted in the Paediatric medicine department of a rural tertiary care hospital of West Bengal. The duration of the study was one year, from January, 2015 to December, 2015.

All children in the age group of less than or equal to 12 years, presenting to the paediatric emergency with definite history of poisoning were included in the study. Poisoning due to insect or animal bite was excluded from the study. This was a retrospective, observational study. Data was obtained from hospital records and the admission register of paediatric emergency, wards and paediatric intensive care unit (PICU) (for the year 2015). Some information was also collected from available patient files.

Demographic data (age, gender and time of arrival at hospital) was noted in each case. Further information was obtained on the type of poison, source of poison, clinical symptoms, duration of hospital admission and outcome in those children known to be suffering from accidental poisoning.
Data was entered in the Microsoft excel sheet and analysed by using statistical software SPSS version 17. Frequencies and percentages were obtained from categorical variables and mean $\pm S D$ were reported for continuous variables.

\section{Results}

During the study period 393 patients reported with ingestion, inhalation or contact with toxic materials. This was $1.9 \%$ of all pediatric admissions during the said period. (Figure-1) The mean age at presentation was $3.1 \pm 2.1$ years. The highest percentage of poisoning was in the $1-3$ year age group (59.6\%), as compared to $23.4 \%$ in $4-6$ years, $9.9 \%$ in $7-9$ years, $5.1 \%$ in $10-12$ years and $5.1 \%$ in the $0-1$ year age groups. (Table-1) The minimum age and the maximum age were 2 months and 12 years respectively. The male:female ratio of the 393 children was 1.4:1. Majority of the patients were from rural areas with rural:urban ratio being 2.7:1. The months of maximum incidence were May-June.

In majority of the patients admitted, the route of poisoning was through ingestion (93\%). Time interval to reach hospital after the poisoning ranged from 30 mins to 18 hours, the mean being 9.8 hours. Accidental intake was responsible for almost all the cases (97.5\%). Eight children $(2.1 \%)$ intentionally ingested poisons, mostly being pharmaceutical agents and agricultural pesticides to attempt suicide. Most of them were in the age group 10-12 years, females outnumbering males.

Regarding the type of agents involved volatile hydrocarbons (mostly kerosene and terpene, spirit) accounted for the highest proportion of poisonings (153 cases, 38.9\%), followed by agricultural pesticides like organophosphates, organochlorines, carbamates (60 cases, 15.3\%), and drugs (49 cases, 12.5 $\%)$. Household insecticides and rodenticides like pyrethroids, zinc phosphide/rat poison, bromadiolone (9.9\%); vegetable poisons such as Datura, Lathyrus sativus (8.7\%); household items, cleaning agents e.g. phenyl, detergents, disinfectants $(6.6 \%)$, and corrosives like hydrochloric, sulphuric and nitric acids $(2.8 \%)$ were the other substances implicated(Figure 2). Among drugs and pharmaceutical agents responsible the most important were acetaminophen, sedatives (clonazepam), iron formulations, antipsychotics, antihistaminics (cyproheptadine), and anticonvulsants (mostcommon phenobarbitone).

Number of patients who were asymptomatic on presentation was 182 (46.3\%). But, they had history of exposure to poisonous agents. So, they were admitted 
for observation. The most common symptoms in the poisoned patients were related to the Gastrointestinal system (vomiting, abdominal pain \& diarrhoea: 36.5 $\%)$; followed by the nervous system including both Central Nervous System (seizure, altered sensorium) and Peripheral Nervous System (tingling, numbness: $26.6 \%$ ) and the respiratory system(cough, respiratory distress, chest pain: $23.7 \%$ ). Few patients (6) developed cardiovascular symptoms and signs during stay which included features of circulatory failure and arrhythmias, with cardiac arrest in two patients. One child had acute renal failure(Table-2).

Of the 211 patients who presented with or developed symptoms of poisoning during stay, 40 patients had serious complications most commonly related to the respiratory(severe respiratory distress, respiratory failure, ARDS) or CNS(altered sensorium, refractory seizures)and these patients were transferred to PICU for intensive care and monitoring. Thirteen patients required intubation with mechanical ventilation. One patient required haemodialysis. The stable children were discharged and followed up in Paediatric outpatient department. Some patients $(29 ; 7.4 \%)$ left against medical advice (LAMA) due to their financial or domestic problems. A total of eight patients died, the most important cause being respiratory failure (4), followed by cardiac arrest (2), renal failure (1), and severe CNS depression. The main causes implicated were organophosphates, volatile hydrocarbons and drugs.

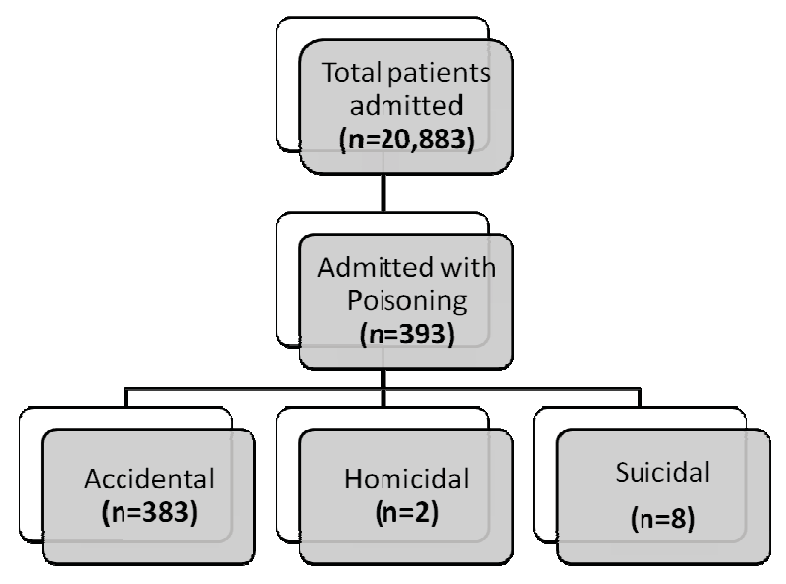

Fig 1: Showing Flow of patients

\section{Percentage of different causes of poisoning}

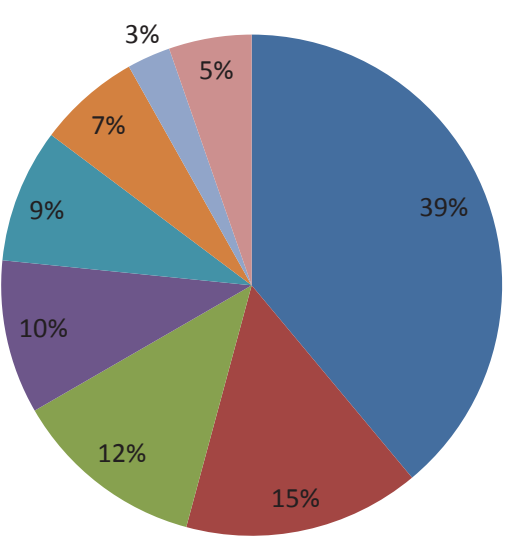

- Volatile Hydrocarbons

- Agricultural Pesticides

Drugs

- Household

Insecticides/Rodenticides

Vegetable Poisons

Fig 2: Pie chart depicting percentage of different causes of paediatric poisoning 
Table 1: Showing Epidemiological data in different age groups

\begin{tabular}{ccccccc}
\hline Age Group (years) & Male/Female & Rural/Urban & Percentage & Accidental & Homicidal & Suicidal \\
\hline Mean Age- 3.1 2.1 years & & & & & & \\
\hline $0-1$ & $6 / 2$ & $5 / 3$ & $2.1 \%$ & 7 & 1 & 0 \\
\hline $1-3$ & $132 / 102$ & $178 / 56$ & $59.6 \%$ & 233 & 1 & 0 \\
\hline $4-6$ & $57 / 35$ & $66 / 26$ & $23.4 \%$ & 92 & 0 & 0 \\
\hline $7-9$ & $21 / 18$ & $24 / 15$ & $9.9 \%$ & 38 & 0 & 1 \\
\hline $10-12$ & $11 / 9$ & $12 / 8$ & $5.1 \%$ & 13 & 0 & 7 \\
\hline Total & 393 & $\mathbf{3 9 3}$ & $\mathbf{1 0 0} \%$ & & & \\
\hline
\end{tabular}

Table 2: Showing symptoms related to different etiological agents

\begin{tabular}{lccccc}
\hline Type of Poison & Asymptomatic & GI & Respiratory & CVS & CNS \\
\hline Volatile Hydrocarbons & 61 & 33 & 42 & 2 & 6 \\
\hline Agricultural Pesticides & 22 & 12 & 4 & - & 10 \\
\hline Drugs & 25 & 10 & - & 2 & 11 \\
\hline Household Insecticides/Rodenticides & 18 & 8 & 2 & - & 6 \\
\hline Vegetable Poison & 17 & 5 & - & 2 & 4 \\
\hline Household items/cleansing agents/ & 18 & 4 & - & - & 1 \\
detergents/disinfectants & 4 & 3 & 2 & - & - \\
Corrosives & 17 & 2 & - & - & - \\
\hline Unknown & $\mathbf{1 8 2}$ & $\mathbf{7 7}$ & $\mathbf{5 0}$ & $\mathbf{6}$ & $\mathbf{3 8}$ \\
\hline Total & & & & & \\
\hline
\end{tabular}

\section{Discussion}

Poisoning in children is a global problem. In our study total 393 patients presented with history of acute poisoning during one year study period, whereas other local and regional studies from Bankura, Burdwan (at the same centre where this study was conducted), New Delhi and Nepal showed 40, 134, 111 and 122 admissions per year respectively ${ }^{9,10,11,12}$. So, sample size was higher in our study in comparison to similar studies.

Accidental poisoning has a strong age predilection. This problem is particularly common in toddlers and older children in the age group of 1-5 years. Children of this age group have increased tendency to eat or drink any object or substance due to strong oral orientations. They are also very keen to explore the environment ${ }^{1}$.

In our study the incidence was more common in the age group of 1-3 years, as seen in almost all the other studies ${ }^{9,10,11}$. Only about $15 \%$ of the cases admitted belonged to the age group above 6 years. Some studies showed that children less than five years were commonly affected ${ }^{12,13}$. The mean age of presentation in our study was 3.1 years, which was close (2.8) to other regional studies ${ }^{1}$. In our study males were higher in number. The overall male preponderance has been found in most of the other studies ${ }^{1}$. Oral route remains the most commonly involved in $97.5 \%$ accidental cases of poisoning in our study.
Poisonous agents show geographical variations influenced by economic status. In our study volatile hydrocarbons in general and kerosene oil in particular was the most common etiological agent responsible. Kerosene oil is the commonest poisonous agent for accidental ingestion in children living in developing countries $^{11,14,15}$. Especially in our hospital, which caters to the needs of a large population of rural South Bengal, such poisonings were found to be very common and did not differ much from a similar study done at our college by Sarkar and colleagues almost two decades back ${ }^{10}$. Kerosene oil is a hazardous substance according to the Environmental Protection Agency of USA. It is a petroleum hydrocarbon ${ }^{15}$. The toxic effects on the body are due to its chemical properties of lower viscosity and surface tension.

Agricultural pesticides (Organophosphorus poisoning) and pharmaceutical products were found to be the second and third most common agent respectively. Organophosphorus poisoning is the commonest cause of poisoning in some other studies ${ }^{7}$. The symptomatology is due to irreversible blockage of both cholinesterase and pseudo cholinesterase activity. So, acetylcholine gets accumulated at synapses, which causes over stimulation initially but subsequently lead to exhaustion and disruption of neurotransmission in both central and peripheral nervous system ${ }^{16}$. Pharmaceutical products have been found to be the commonest poisoning agent in some studies ${ }^{7,15,17}$. An 
increased incidence of ingestion of pharmaceutical agents or drugs was mainly due to their improper storage by parents and grandparents. Household substances have been reported as the leading cause of paediatric poisoning from Japan and india ${ }^{18,19}$.

Gastrointestinal symptoms are the most frequent complaint in our study, which is similar to other studies ${ }^{1,19}$. However, one study revealed that neurological signs including lethargy and unconsciousness were also an important factor for urgent admission and management ${ }^{4}$. About $46 \%$ of the admitted patients were asymptomatic on presentation and more than $50 \%$ of the patients were discharged within 24 hours. Although poisoning is a common occurrence in childhood, very few patients require hospital admission and number of admission to PICU is even fewer"

The sample size in our study was comparatively higher than the West $^{6}$. This may be due to lack of awareness in the community. In our study, 29 patients left against medical advice. Financial constraints and domestic problems were the main reasons behind this. The case fatality rate in our study was $2.1 \%$ which in comparison to similar studies is relatively low.

\section{References}

1. Abbas SK, Tikmani SS, Siddiqui NT. Accidental poisoning in children. J Pak Med Assoc 2012;62:33134.

2. CDC. Poisoning among young children - United States. MMWR 1984;33: 129-31.

3. Fazen LE 3rd, Love FH Jr, Crone RK. Acute poisoning in a children's hospital: a 2-year experience. Pediatrics 1986;77:144-51.

4. Walton WW. An evaluation of the poison prevention packaging act. Pediatrics 1982;69:363-70.

5. Berman LB. Epidemiology of serious poisonings. Clin Toxicol Rev 1983;5:

6. Osterhaudt KC, Shannon M, Henretig FM. Toxicological emergencies. In: Fleisher GR, Ludwig $\mathrm{S}$, (edi) Textbook of Pediatric emergency medicine. 4th ed. Philadelphia: Lippincott Williams and Wilkins 2000; pp 887-97.

7. Aslam M, Baloch GR, Hussain W. Accidental poisoning in children. Pak Paed J 2002; 26:67-70.

8. Hamid MH, Butt T, Baloch GR, Maqbool S. Acute poisoning in children. $J$ Coll Physicians Surg Pak 2005;15:805-8.

9. Barat D, Sarkar AK. A study of accidental poisoning in children in West Bengal. Indian $J$ Pediatr 1977; 44:278-83.

10. Sarker AK, Ghosh S, Barik K. A study of accidental poisoning (in children) in a rural medical college hospital of West Bengal. Indian J Pub Health 1990;34:159-62.
Since our study was done retrospectively, it is possible that the exact types of drugs have not been noted in patients' records. There is need of further epidemiological studies.

\section{Conclusion}

Incidence of poisoning was higher in our study in comparison to other studies with majority in the 1-3 year age group. Volatile hydrocarbons were the commonest cause of poisoning while $\mathrm{Gl}$ system was the most common system involved. Total mortality in our study was eight.

\section{Key Messages}

The epidemiological characteristics of paediatric poisoning differ from country to country. So more epidemiological studies in each country and each region is necessary to determine how this health problem can be prevented. Socio-demographic risk factors responsible in our country need to be addressed as the most important issues regarding paediatric poisoning in healthcare delivery system, and national programmes need to be implemented to counter the increasing morbidity and mortality associated with this social mishap.

11. Kohli U, Kuttiat VS, Lodha R, Kabra SK. Profile of childhood poisoning at a tertiary care centre in North India. Indian J Pediatr 2008;75:791-94.

12. Budhathoki S, Poudel P, Shah D, Bhatta NK, Dutta AK, Shah GS, et al. Clinical profile and outcome of children presenting with poisoning or intoxication: a hospital based study. Nepal Med Coll J 2009;11:1705.

13. Khare M, Bhide M, Ranade A, Jaykar A, Panicker L, Patnekar PN. Poisoning in children--analysis of 250 cases. J Postgrad Med 1990;36:203-6.

14. Fernando $R$, Fernando DN. Childhood poisoning in Sri Lanka. Indian J Pediatr 1997;64:457-60.

15. Babar MI, Bhait R.A, Cheema M.E. Kerosene oil poisoning in children. $J$ Coll Physicians Surg Pak 2002;12:472-6.

16. Hussain AM, Sultan T. Organophosphorous insecticide poisoning: management in surgical intensive care unit. J Coll Physicians Surg Pak 2005; 15:100-2.

17. Chatsantiprapa K, Cokkanapitak J, Pinpradit N. Host and environmental factors for exposure to poisons: a case-control study of preschool children in Thailand. Inj Prev 2001;7:214-47.

18. Goto K, Endoh Y, Kuroki Y, Yoshioka T. Poisoning in children in Japan. Indian J Pediatr 1997;64:461-8.

19. Khadka SB, Khadka SB. A study of poisoning cases in emergency Kathmandu Medical College Teaching Hospital. Kathmandu Univ Med J (KUMJ) 2005;3:388-91. 